\title{
Influence of Substrate Bias Voltage on the Properties of Sputtered Aluminum-Scandium Thin Sheets
}

\author{
Julien Kovac ${ }^{*}$, Heinz-Rolf Stock, Hans-Werner Zoch
}

Oberflaechentechnik, Stiftung Institut für Werkstofftechnik (IWT), Bremen, Germany.

Email: *kovac@iwt-bremen.de

Received December $19^{\text {th }}, 2011$; revised January $11^{\text {th }}, 2012$; accepted January $27^{\text {th }}, 2012$

\begin{abstract}
Thin sheets $(20 \mu \mathrm{m}-30 \mu \mathrm{m})$ of an aluminum-scandium alloy were manufactured by magnetron sputtering with a homogeneous thickness distribution. The influence of bias voltage on the sheet properties was investigated. Steel sheets of $100 \mu \mathrm{m}$ were employed as substrate and were coated in a dc magnetron sputtering unit fitted with a rectangular target of aluminum $2.0 \mathrm{w} \%$ scandium master alloy. After deposition, the substrates were dissolved in an oxidizing medium and thus freestanding aluminum-scandium thin films were obtained. The homogeneous thickness was achieved by a reciprocal movement of the substrate. The influence of a radio frequency bias voltage on the coating properties was investigated. The bias voltage resulted in an important coarsening of the columnar structure as well as an increase of the roughness and hardness. Additionally, a low bias voltage could intensively reduce the coating defect density without altering too much the sheet properties.
\end{abstract}

Keywords: Aluminum-Scandium Alloy; Magnetron Sputtering; Freestanding Thin Films; Bias Voltage

\section{Introduction}

In the recent years, the trend of miniaturization of mechanical or electrical systems has increased the demand on micro components. Micro forming processes are a suitable technology for the mass productions of these parts [1] but often require sheets of high strength materials with a thickness below $30 \mu \mathrm{m}$. A common way to produce sheets of this thickness is rolling, which allows the availability of sheets of common materials such as $\mathrm{Al}$ 99.5 or E58 copper in the desired thickness, but these materials have a limited strength.

On the other hand, aluminum-scandium alloy is a high strength material and has shown a promising potential for the manufacturing of micro components [2]. The addition of a small amount of scandium in aluminum results in the precipitation of fine $\mathrm{AlSc}_{3}$ precipitates which have low lattice mismatch with the aluminum matrix and causes a high strength as well as grain refining and anti-recrystallization properties to the material $[3,4]$. Because of its high strength, this material cannot be rolled down to the required thickness for micro cold forming processes. A possible way to overcome this difficulty is to produce thin sheets of aluminum-scandium alloy in the form of freestanding films, using dc magnetron sputtering as deposition method.

A previous study on the topic [5] has shown that mag-

"Corresponding author. netron sputtering is a suitable manufacturing method to produce aluminum-scandium thin sheets with excellent tensile properties. A tensile strength of about $350 \mathrm{MPa}$ was measured in the post-deposition state and an artificial ageing treatment at $573 \mathrm{~K}$ for 1 hour increased this value up to about $400 \mathrm{MPa}$. But these sheets show two disadvantages. Firstly, the sheets were produced with a motionless substrate holder. This leads to an inhomogeneous distribution of the film thickness. In order to produce sheets with a homogeneous thickness distribution it is thus necessary to move the substrate during the deposition process. The classical solution consists of rotating the substrate around the deposition chamber. However, this technique has the disadvantage of a considerably reduced deposition rate. A more satisfying solution is to use a reciprocal movement. Thus, the substrate oscillates around the target and less sputtered material is lost. The second disadvantage is the density of coating defects which crucially reduce the overall strength. It is thus interesting to keep the coating defect density as low as possible. A possible way to do so is to use a substrate bias during the deposition process as some authors did for the production of $\mathrm{CrN}$ and $\mathrm{CrCN}$ films [6]. However, the ion bombardment induced by the bias voltage can also result in a significant modification of the film morphology and the mechanical properties which both can influence the micro forming process. 
The present study outlines the sputtering of aluminumscandium thin sheets with homogeneous thickness distribution and limited coating defects. The influence of the bias voltage on the morphology, the roughness, the hardness and the coating defect density is investigated.

\section{Experimental}

\subsection{Fabrication of the Aluminum-Scandium Sheets}

Aluminum-scandium sheets were deposited in a dc magnetron sputtering unit fitted with a rectangular target of aluminum $2.0 \mathrm{w} \%$ Sc master alloy with a size of $88 \times$ $488 \times 8 \mathrm{~mm} .150 \times 300 \mathrm{~mm}^{2}$ substrate sheets of unalloyed steel with a thickness of $100 \mu \mathrm{m}$ were used. The distance between the target and the substrate is $50 \mathrm{~mm}$. The deposition was carried out under an argon pressure of $0.4 \mathrm{~Pa}$ with a target power of $1 \mathrm{~kW}$. The samples were then immersed in a $65 \%$ nitric acid solution in order to dissolve the steel substrate so that freestanding aluminum-scandium films are obtained. Glow discharge optical spectroscopy (GDOS) measurements revealed that the produced sheets have about the same composition as the target.

In order to produce sheets with a homogeneous thickness distribution a reciprocal motion was applied to the substrate. As can be seen in Figure 1 the reciprocal motion can be described by its amplitude $\varphi$ which is the angle between the center of the target and the center of the substrate. Hence during the deposition process, the substrate holder moves from the position $-\varphi$ to the position $+\varphi$ and then returns to the position $-\varphi$ and the complete cycle is repeated until the end of the deposition process. In this manner four sheets were deposited with different motion amplitudes between $0^{\circ}$ (no motion) and $23^{\circ}$ and a constant angular speed of $108 \mathrm{~min}^{-1}$ during 3 hours.

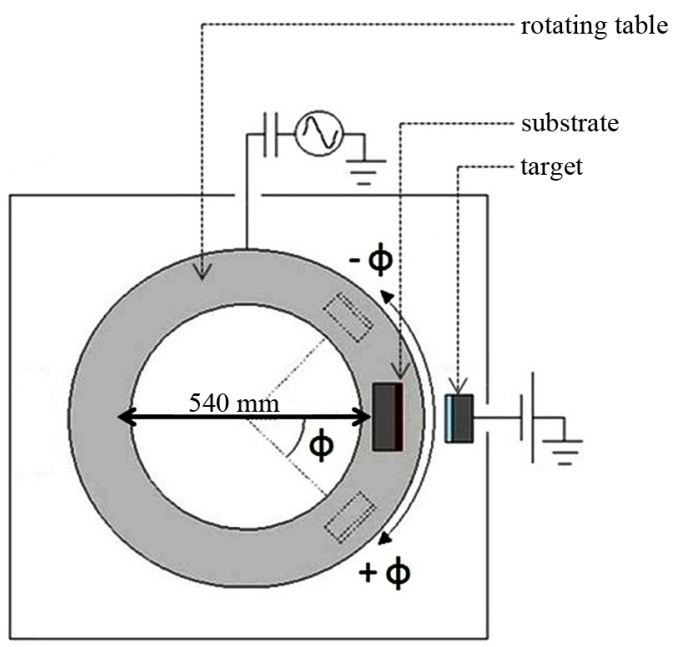

Figure 1. Sketch of the vertical section of the magnetron sputtering unit.
Thickness profiles were measured in the width direction of the samples using an electromagnetic induction method; the results are featured on Figure 2. In the case of a motionless substrate $\left(0^{\circ}\right)$ or a movement of small amplitude $\left(8^{\circ}\right)$, a very uneven thickness distribution is observed. A maximum thickness of $22 \mu \mathrm{m}$ was obtained at a position corresponding with the middle of the target and a significant drop of the thickness towards the edges of the sheet. With an amplitude of $15^{\circ}$ both, the maximum thickness and the thickness decline toward the edges are reduced. Finally, the sheet produced with an amplitude of $23^{\circ}$ showed a constant thickness of $8 \mu \mathrm{m}$, therefore this amplitude was used in the deposition experiments.

\subsection{Influence of the Substrate Bias}

During magnetron sputtering of the aluminum-scandium sheets a radio frequency bias voltage $(13.56 \mathrm{MHz})$ was applied to the substrate. Five different bias voltages inthe range $0 \mathrm{~V}$ to $-250 \mathrm{~V}$ were applied. The film morphology was investigated with scanning electron microscopy (Camscan MV2300, EO Scan) and roughness measurements were carried out using atomic force microscopy (Explorer, Veeco Instruments). Hardness measurements were performed on the cross section of the sheets under a load of $8 \mathrm{mN}$ with a micro-hardness tester (Fischerscope H100C, Fischer). Moreover, in some sheets, the coating defect density was evaluated using 20 randomly selected SEM pictures.

\section{Results}

\subsection{Morphology and Roughness}

Five sheets were produced with different bias voltages. The application of a bias voltage causes an ion bombardment of the film surface which causes a resputtering of the surface atoms and thus decreases the deposition rate [7]. For this reason, the sputtering time was varied so that the film thickness is kept in a reasonable range of 23 to $28 \mu \mathrm{m}$. The parameters used for the deposition of these sheets are presented in Table 1. The film morphology was

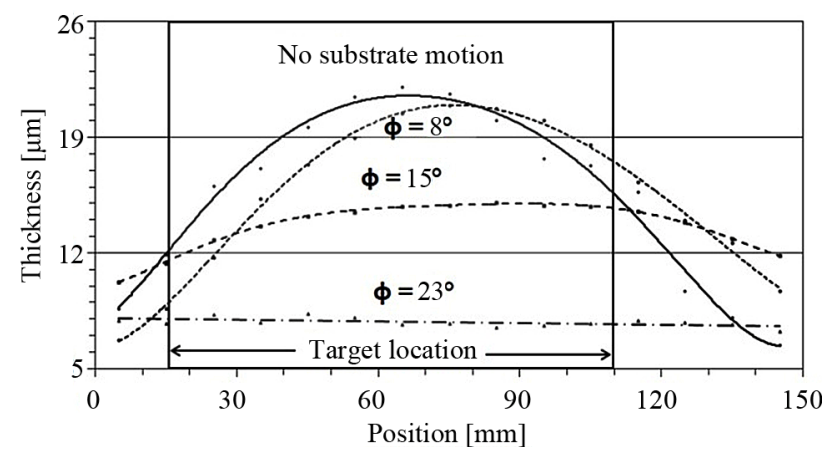

Figure 2. Thickness profiles in the width direction of sheets produced with different motion amplitudes. 
investigated with scanning electron microscopy. Pictures of the free surface and of the cross section of the samples $\mathrm{A}, \mathrm{C}$ and $\mathrm{E}$ are featured in Figure 3. The bottom side of the samples (that was in contact with the substrate) shows a pseudo-amorphous or fine crystalline structure. A few micrometers above, this structure evolved into a columnar structure with faceted shapes on the free surface. This columnar morphology is relatively fine in the case of a not biased substrate (sample A). The application and further increase of the substrate bias results in a coarsening of the columns presenting a flattened shape at the surface, although the surface seems to be more irregular. This latter observation is confirmed by the AFM measurements in Figure 4. The increase of the applied bias results in an augmentation of the free surface roughness. This rise is relatively limited for small bias voltage but increases dramatically for values above $-150 \mathrm{~V}$. The contact surface is in every case smoother than the free surface and presents a constant roughness corresponding to the substrate roughness.

Table 1. Process parameters and resulting thicknesses.

\begin{tabular}{cccc}
\hline $\begin{array}{c}\text { Sample Designa- } \\
\text { tion }\end{array}$ & $\begin{array}{c}\text { Bias Voltage } \\
(-\mathrm{V})\end{array}$ & $\begin{array}{c}\text { Deposition Time } \\
(\mathrm{min})\end{array}$ & $\begin{array}{c}\text { Film Thickness } \\
(\mu \mathrm{m})\end{array}$ \\
\hline A & 0 & 420 & 27 \\
B & 100 & 460 & 23 \\
C & 150 & 480 & 25 \\
D & 200 & 500 & 27 \\
E & 250 & 520 & 28 \\
\hline
\end{tabular}

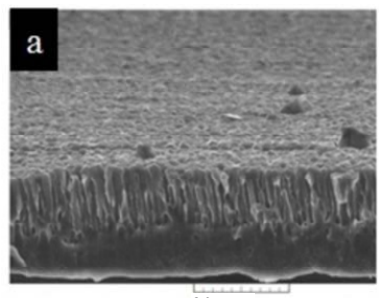

$20 \mu \mathrm{m}$

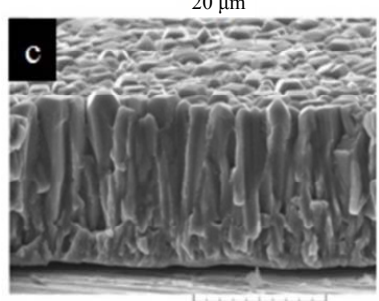

$20 \mu \mathrm{m}$

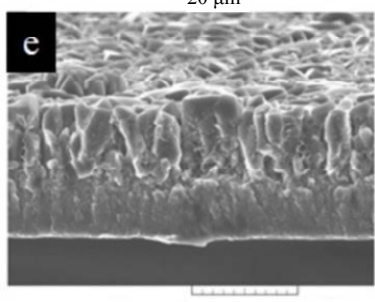

$20 \mu \mathrm{m}$
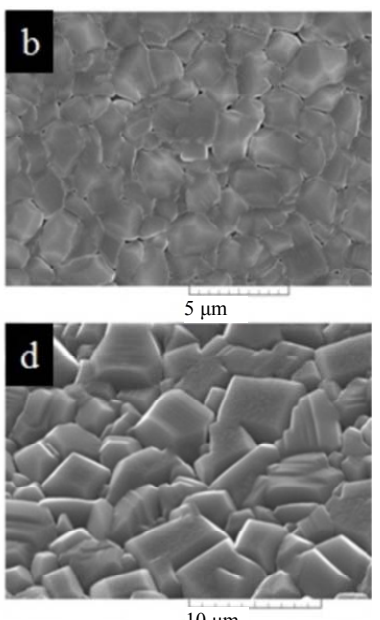

$10 \mu \mathrm{m}$

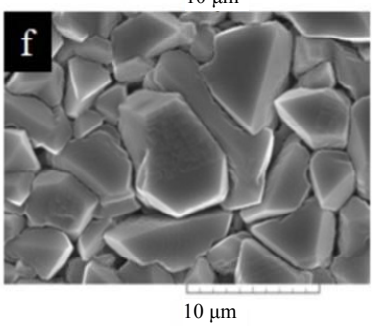

Figure 3. Cross sections and free surfaces of the sheets $A$ (a, b), $C(c, d)$ and $E(e, f)$.

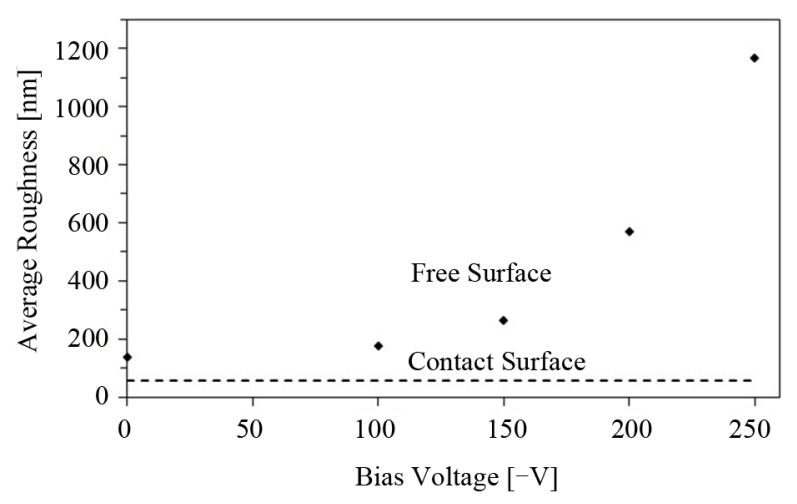

Figure 4. Free surface roughness and contact surface roughness versus bias voltage.

\subsection{Hardness Measurements}

The results of the micro-hardness measurements performed on the cross section of the sheets are represented in Figure 5. The sample A presents a hardness of about 150 $\mathrm{HV}$. It can be seen that the application of a bias voltage leads to an important increase of hardness. Indeed, the sample B shows a hardness of about $250 \mathrm{HV}$, whereas the samples C, D and E show exceptionally high hardness values of 328, 474 and $635 \mathrm{HV}$. The samples D and E were indeed very brittle and many cracks and a partial delimitation could be observed after deposition and therefore were not suitable for sheet production.

\subsection{Coating Defect Density}

The coating defect density was determined from 20 SEM images randomly selected on the free surface of samples A, B and C. Typical examples of coating defects can be seen on Figure 6. Theses coating defects are called hillocks and present a conical shape under the free surface and a bump sticking out the surface. The hillock densities found in the samples A, B and C are depicted in Table 2 and its evolution with the bias voltage is illustrated through exemplary SEM pictures (Figure 7). In the sample A, a very high density of about $835 \mathrm{~mm}^{-2}$ is measured. The application of a $-100 \mathrm{~V}$ bias voltage (sample B) results in an important decrease of the hillock density down to $22 \mathrm{~mm}^{-2}$. A further rise of the bias voltage up to -150 $\mathrm{V}$ (C) does not lead to further improvement.

\section{Discussion}

As can be seen, the film properties are strongly influenced by the ion bombardment induced by the substrate bias. An important coarsening of the columnar structure (Figure 3) and a more irregular surface morphology resulted from the increase of the bias voltage. The direct consequence of the morphology changes is a rise of the free surface roughness (Figure 4) which has a significant influence on the friction coefficient as measured by Vol- 
lertsen et al. [2]. Micro deep drawing experiments realized to date [2] suggest that a smoother roughness is appreciable since it seems to reduce the punch force required in the process. The roughness augmentation observed might be therefore detrimental for the process. However, the increase of the roughness is quite limited in the range of bias voltage from 0 to $-150 \mathrm{~V}$.

Another consequence of the increase of the bias voltage is the hardening of the sheets. The augmentation of the hardness (Figure 5) suggests an important strengthening of the material which is itself favorable for the process. However, it is likely to reduce the deformation as well. Thus it is important to keep the hardness in a reasonable extent so that the sheets keep enough ductility for the micro cold forming process. In samples A and B the measured hardness remains in the range of the typical values for such sheets, whereas the hardness of the three other samples clearly exceeds this range. Therefore, it could be considered that the bias voltage must not exceed $-100 \mathrm{~V}$ to produce suitable sheets.

The application of a bias voltage to the substrate also influences the hillock density (Figure 6, Figure 7 and

Table 2. Hillock density of the samples A, B and C.

\begin{tabular}{ccc}
\hline $\begin{array}{c}\text { Sample } \\
\text { designation }\end{array}$ & Bias voltage $(-\mathrm{V})$ & Hillocks density $\left(\mathrm{mm}^{-2}\right)$ \\
\hline A & 0 & 817 \\
B & 100 & 22 \\
C & 150 & 266 \\
\hline
\end{tabular}

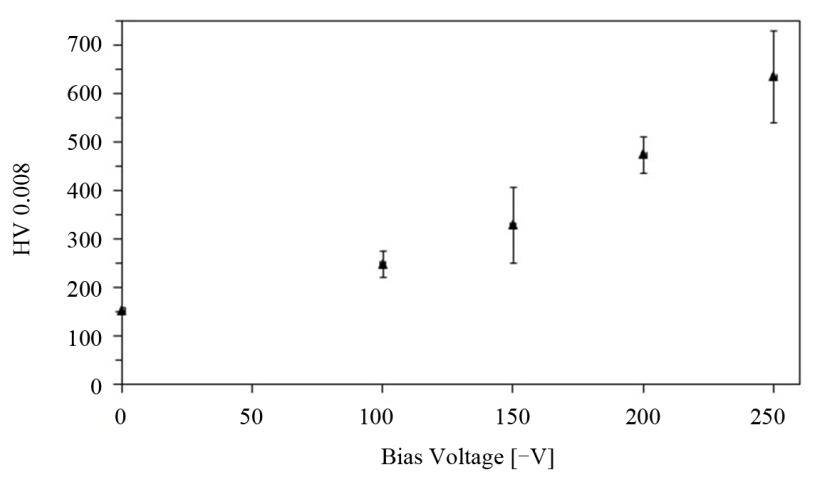

Figure 5. Micro-hardness of the sheets versus applied bias voltage.

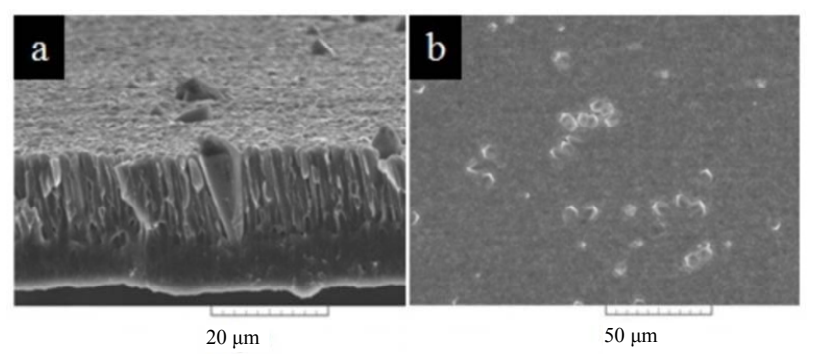

Figure 6. Coating defects viewed in the cross section (a) and on the free surface (b).

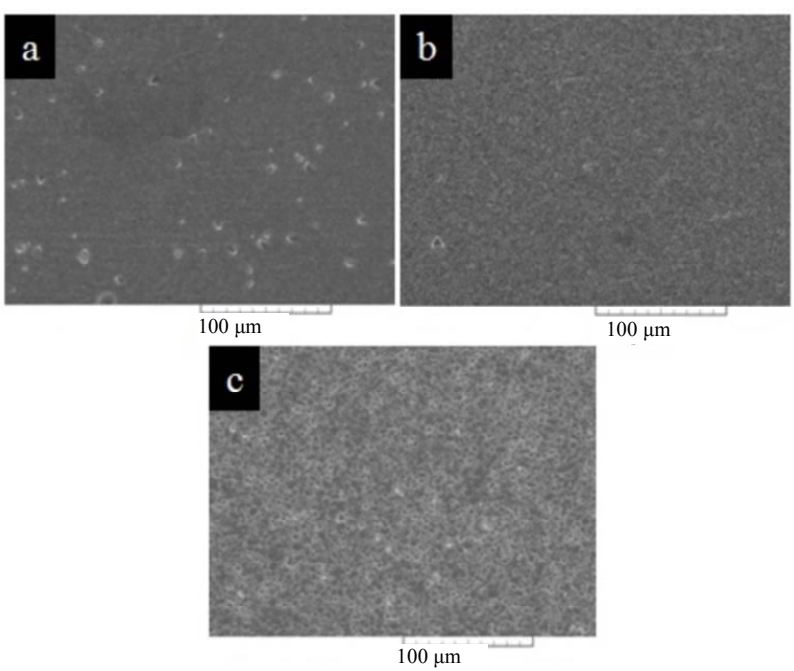

Figure 7. SEM pictures of coating defects on samples A (a), $B$ (b) and C (c).

Table 2). The hillock formation was reported to be correlated with the relaxation of compressive stress occurring during the deposition process [8]. The mechanism of formation of these hillocks is still a subject of controversy; indeed for some authors [9] the implicated mechanism is diffusional as for others [10] the formation mechanism is plastic deformation. In the case of the present study, the hillocks are assumed to appear partially because of the substrate heating. Actually, since no temperature controlling unit is installed on the substrate holder, the loss of kinetic energy from the neutrals and ions impinging on the substrate is mainly turned into thermal energy and a heating of the substrate occurs until an equilibrium temperature is reached. During the heating phase, the difference of thermal expansion coefficients between the aluminum-scandium film and the steel substrate $\left(24 \times 10^{-6} \mathrm{~K}^{-1}\right.$ for pure aluminum and $13 \times 10^{-6}$ $\mathrm{K}^{-1}$ for steel) causes the appearance of compressive stress in the aluminum-scandium thin film. The other possible source of compressive stress is the film bombardment with energetic particles due to a too low pressure and conesquently the absence of thermalization [11]. The hillock density measurements have shown that the sample B produced under a bias voltage of $-100 \mathrm{~V}$ presents very few hillocks in comparison to the sample A, produced without substrate bias. This result can be correlated with the increase of hardness measured in the sample B. As it was suggested by Lee et al. [12], the triggering mechanism of the hillock formation is the relaxation of compressive stress at the yielding point. The higher hardness in the sample B suggests an increase of the yield stress, thus the sample B shows more resistance to hillocks formation than the sample A. Sample C produced under a bias voltage of $-150 \mathrm{~V}$ also shows fewer hillocks than sample A, however its hillock density is significantly 
higher compared to sample B. This augmentation of the hillock density might be the result of the supplemental heating induced by the higher energy of the bombarding ions.

\section{Conclusions}

- Thin sheets of aluminum-scandium alloy were produced by dc magnetron sputtering. A reciprocal movement of the substrate allows the production of sheets with homogeneous thickness distribution.

- The application of a radio frequency bias voltage of $-100 \mathrm{~V}$ increases the hardness of the sheet and reduces the hillock density.

- Higher bias voltages don't reduce further the hillock density and results in too high roughness and hardness values.

\section{Acknowledgements}

The authors gratefully acknowledge financial support by DFG (German Research Foundation) for project A1 within the Collaborative Research Center SFB 747 Micro Cold Forming-Processes, Characterisation and Optimisation.

\section{REFERENCES}

[1] F. Vollertsen, Z. Hu, H. Schulze Niehoff and C. Theiler, "State of the Art in Micro Forming and Investigations into Micro Deep Drawing," Journal of Materials Processing Technology, Vol. 151, No. 1-3, 2004, pp. 70-79. doi:10.1016/j.jmatprotec.2004.04.266

[2] F. Vollertsen, Z. Hu, H.-R. Stock and B. Koehler, "On the Limit Drawing Ratio of Magnetron Sputtered Aluminium-Scandium Foils within Micro Deep Drawing," Production Engineering Research and Development, Vol. 4, No. 5, 2010, pp. 451-456.doi:10.1007/s11740-010-0229-2

[3] J. Royset and N. Ryum, "Scandium in Aluminium Alloys," International Materials Reviews, Vol. 50, No. 1, 2005, pp. 19-44. doi:10.1179/174328005X14311

[4] K. Venkateswarlu, L. C. Pathak, A. K. Ray, G. Das, P. K. Verma, M. Kumar and R. N. Ghosch, "Microstructure,
Tensile Strength and Wear Behavior of Al-Sc Alloy," Materials Science and Engineering A, Vol. 383, No. 2, 2004, pp. 374-380. doi:10.1016/j.msea.2004.05.075

[5] H.-R. Stock, B. Koehler, H. Bomas and H.-W. Zoch, "Characteristics of Aluminium-Scandium Alloy Thin Sheets Obtained by Physical Vapor Deposition," Materials and Design, Vol. 31, Suppl. 1, 2010, pp. S79-S81. doi:10.1016/j.matdes.2010.04.040

[6] B. Warcholinski, A. Gilewicz, J. Ratajski, Z. Kuklinski and J. Rochowicz, "An Analysis of Macroparticle-Related Defects on CrCN and CrN Coatings in Dependence of the Substrate Bias Voltage," Vacuum, 2011, in press. doi:10.1016/j.vacuum.2011.04.023

[7] Q. Kong, L. Ji, H. Li, X. Liu, Y. Wang, J. Chen and H. Zhou, "Influence of Substrate Bias Voltage on the Microstructure and Residual Stress of CrN Films Deposited by Medium Frequency Magnetron Sputtering," Materials Science and Engineering B, Vol. 176, No. 11, 2011, pp. 850-854. doi:10.1016/j.mseb.2011.04.015

[8] J. A. Thornton and D. W. Hoffman, "Stress-Related Effects in Thin Films," Thin Solid Films, Vol. 171, No. 1, 1989, pp. 5-31. doi:10.1016/0040-6090(89)90030-8

[9] F. Ericson, N. Kristensen, J.-A. Schweitz and U. Smith, "A Transmission Electron Microscopy Study of Hillocks in Thin Aluminum Films," Journal of Vacuum Science and Technology B, Vol. 9, No. 1, 1991, pp. 58-63. doi:10.1116/1.585790

[10] S.-J. Hwang, W. D. Nix and Y.-C. Joo, "A Model for Hillock Growth in Al Thin Films Controlled by Plastic Deformation," ActaMateriala, Vol. 55, No. 15, 2007, pp. 5297-5503. doi:10.1016/j.actamat.2007.05.046

[11] R. E. Cuthrell, D. M. Mattox, C. R. Peeples, P. L. Dreike and K. P. Lamppa, "Residual Stress Anisotropy, Stress Control, and Resistivity in Post Cathode Magnetron Sputter Deposited Molybdenum Films," Journal of Vacuum Science and Technology A, Vol. 6, No. 5, 1988, pp. 29142920. doi:10.1116/1.575451

[12] S.-L. Lee, J.-K. Chang, Y.-C. Cheng, K.-Y. Lee and W.-C. Chen, "Effects of Scandium Addition on Electrical Resistivity and Formation of Thermal Hillocks in Aluminum Thin Films," Thin Solid Films, Vol. 519, No. 11, 2011, pp. 3578-3581. doi:10.1016/j.tsf.2011.01.272 